\title{
ESTUDO ELETROQUÍMICO DE UM NOVO BANHO GALVÂNICO DE ZINCO ALCALINO LIVRE DE CIANETOS
}

Gecílio P. da Silva, Nacélio S. Freire, Diogo E. de Matos, Adriana N. Correia e Pedro de Lima-Neto*

Departamento de Química Analítica e Físico-Química, Universidade Federal do Ceará, CP 6035, 60455-970 Fortaleza - CE

Recebido em 6/8/04; aceito em 8/4/05; publicado na web em 10/8/05

\begin{abstract}
ELECTROCHEMICAL STUDY OF A NOVEL CYANIDE FREE GALVANIC PLATING SOLUTION OF ALKALINE ZINC. A systematic electrochemical study of a novel cyanide free galvanic plating solution of alkaline zinc is presented. Cell Hull tests and potentiodynamic linear polarization measurements were carried out to evaluate the influence of operational parameters, such as concentration, current efficiency and degradation of additives. The stability of the bath was assessed by a long term test during 40 $\mathrm{h}$ at $200 \mathrm{~A} \mathrm{~m}^{-2}$. The morphology of the coatings was characterized by scanning electron microscopy. The results showed good performance of the plating solution. The cost is similar to that of the commercial cyanide bath and lower than that of the commercial cyanide free bath.
\end{abstract}

Keywords: zinc plating; electrodeposition; cyanide free.

\section{INTRODUÇÃO}

O zinco é um dos metais mais utilizados industrialmente como revestimento anticorrosivo de materiais ferrosos por apresentar bom desempenho à exposição atmosférica, oferecendo proteção galvânica ao aço, mesmo em regiões de descontinuidades da camada. Adicionalmente, o processo galvânico de obtenção desta camada é relativamente barato quando comparado a outros revestimentos ${ }^{1}$.

Até o início da década de 90, a maioria dos processos de obtenção galvânica dos revestimentos de zinco fazia uso de banhos alcalinos contendo cianetos. A partir de então, em função das crescentes exigências e regulamentações governamentais, tem-se procurado substituir estes banhos por alternativas capazes de minimizar os impactos ambientais ${ }^{2,3}$. Entretanto, apesar dos riscos de acidentes envolvidos no manejo do banho cianídrico e dos imensos danos ambientais causados pelos resíduos industriais produzidos ${ }^{4,5}$, ainda é muito comum a utilização destes nas indústrias galvânicas, motivada principalmente pelo baixo custo operacional quando comparados aos processos isentos de cianetos.

Adicionalmente, os processos cianídricos apresentam outras características importantíssimas para a indústria, tais como elevada taxa de reposição metálica, pré-tratamento simples do metal base, facilidade de controle do processo, utilização de equipamentos pouco sofisticados, uniformidade e ductilidade do depósito ${ }^{6}$. Assim, o grande desafio atual neste campo consiste na substituição do banho cianídrico por processos preferencialmente alcalinos, competitivos em custo e qualidade, uma vez que os processos ácidos à base de cloretos e sulfatos são muito sensíveis às contaminações orgânicas e metálicas, são altamente corrosivos e requerem instalações mais sofisticadas ${ }^{7}$.

Adicionalmente, tem sido relatado na literatura o estudo de eletrólitos alternativos para deposição de zinco em banhos livres de cianeto, usando complexantes orgânicos: etanolamina ${ }^{8}$, acetatos ${ }^{9}$, poliaminas alifáticas quarternárias ${ }^{10}$, trietanolamina ${ }^{11}$ e furfural aldeído $^{11}$. Por outro lado, já existem banhos alcalinos de zinco comerciais livres de cianeto. Entretanto, estes fazem uso de elevada carga de aditivação ${ }^{5,12}$, em substituição ao cianeto, aumentando significativamente os custos de montagem e manutenção ${ }^{13-15}$.

*e-mail: pln@ufc.br
Este trabalho tem por objetivo apresentar o estudo sistemático de um novo banho galvânico alcalino de zinco, livre de cianeto, de baixo custo operacional, investigando a otimização de parâmetros operacionais e finalizando com a operacionalização deste banho em escala industrial.

\section{PARTE EXPERIMENTAL}

$\mathrm{Na}$ formulação deste banho foram definidas as concentrações dos componentes, tomando-se por base as formulações dos banhos convencionais livres de cianetos, que recomendam uma razão em massa de 10:1 entre $\mathrm{NaOH}$ e $\mathrm{Zn}^{2+}$ em solução ${ }^{14}$. Optou-se ainda por uma concentração relativamente alta de zinco em solução $\left(8,0 \mathrm{~g} \mathrm{~L}^{-1}\right)$, uma vez que a prática industrial mostra que baixas concentrações de zinco em solução tornam os banhos comerciais livres de cianeto mais sensíveis às contaminações ${ }^{14}$. Além destes dois constituintes, também foi incluído nesta formulação o carbonato de sódio. A previsão de que a adição de $\mathrm{Na}_{2} \mathrm{CO}_{3}$ traria benefícios relativos à qualidade dos revestimentos e ao custo de sua obtenção foi baseada nas experiências da prática industrial, onde banhos alcalinos de zinco tendem a apresentar melhores condições de deposição em eletrólitos com mais tempo de uso. Isto ocorre devido à formação contínua de carbonato de sódio por reação entre o hidróxido e o dióxido de carbono atmosférico dissolvido no banho ${ }^{15-17}$. Adicionalmente, nos banhos cianídricos a decomposição dos cianetos também conduz à formação de carbonato, melhorando a qualidade do processo ${ }^{15}$. Outro aspecto importante é que o carbonato de sódio é um produto de baixíssimo custo e atóxico. Neste banho foi utilizado um único aditivo comercial, o Alphazinc A- $6^{\circledR}$, para favorecer o aspecto brilhante da camada, na concentração de $30 \mathrm{~mL} / \mathrm{L}$.

A otimização dos parâmetros operacionais do banho formulado foi feita por meio de ensaios em célula de Hull ${ }^{18,19}$ e de ensaios voltamétricos. A avaliação do revestimento obtido a partir do banho formulado consistiu de análise visual, caracterizando a aparência dos depósitos, a cobertura do revestimento ao longo do painel, as regiões de brilho e a influência da corrente aplicada. A caracterização morfológica dos revestimentos foi feita por microscopia eletrônica de varredura (MEV). O banho formulado foi avaliado por meio de ensaio de operação contínua por $40 \mathrm{~h}$ e comparado aos banhos comerciais alcalinos de médio 
cianeto e alcalino livre de cianeto. Para finalizar, foi feito estudo comparativo de custo de montagem, manutenção entre o banho proposto e os dois banhos comerciais ${ }^{14}$.

\section{Composição química dos banhos}

Neste trabalho foram utilizados três banhos: o banho alcalino livre de cianeto estudado (BALCE), banho alcalino cianídrico comercial (BACC) e banho alcalino livre de cianeto comercial (BALCC). A Tabela 1 apresenta a composição química destes banhos.

\section{Experimentos em célula de Hull}

Os experimentos em célula de Hull foram feitos objetivando avaliar o intervalo de densidades de corrente que promove a formação dos melhores eletrodepósitos. O ensaio de célula de Hull faz uso da seguinte equação empírica ${ }^{18,19}$ :

$\mathrm{i}=100 \mathrm{I}(5,102-5,24 \log \mathrm{L})$

onde i é a densidade de corrente em A m ${ }^{-2}$, I é a corrente aplicada em A e L, o comprimento ao longo do painel de eletrodeposição (cátodo) em $\mathrm{cm}$.

Os eletrodepósitos foram obtidos sobre aço carbono 1010 , na temperatura ambiente $\left(\cong 30{ }^{\circ} \mathrm{C}\right)$, sob controle galvanostático no intervalo de densidade de corrente 50 a $1000 \mathrm{~A} \mathrm{~m}^{-2}$ e utilizando uma célula de Hull com capacidade de $267 \mathrm{~mL}$. Os aspectos visuais da camada, levados em consideração nestes experimentos para a seleção das melhores condições de deposição, são brilho, cobertura e aderência. Um diagrama esquemático da célula utilizada é mostrado na Figura 1. Nestes experimentos foram utilizados painéis (cátodo da célula de Hull) com área geométrica de $0,0056 \mathrm{~m}^{2}$ e zinco comercial como ânodo.

Também foram feitas medidas de espessura de camadas ao longo de toda a extensão do painel por método não destrutivo, utilizando-se um medidor de espessuras Mitutoyo NEO DERM, modelo 179-701. A técnica tem como princípio a indução magnética e as medidas são realizadas por contato direto de um sensor com a superfície de interesse.

\section{Ensaios voltamétricos}

A influência da concentração de $\mathrm{Na}_{2} \mathrm{CO}_{3}$ na reação de desprendimento de hidrogênio durante o processo de eletrodeposição foi avaliada por meio de voltametria de varredura linear a $1 \mathrm{mV} \mathrm{s}^{-1}$, em temperatura ambiente. Foram utilizadas soluções nas correspondentes concentrações de hidróxido e carbonato do BALCE (Tabela 1), mas isentas de zinco. Calomelano saturado e lâmina de platina foram utilizados como eletrodos de referência e auxiliar, respectivamente. Os experimentos foram feitos utilizando-se um potenciostato/ galvanostato da Microquímica modelo MQPG01, acoplado a microcomputador para aquisição e tratamento dos dados.

\section{Avaliação da estabilidade operacional do banho}

A avaliação da estabilidade operacional do BALCE foi feita

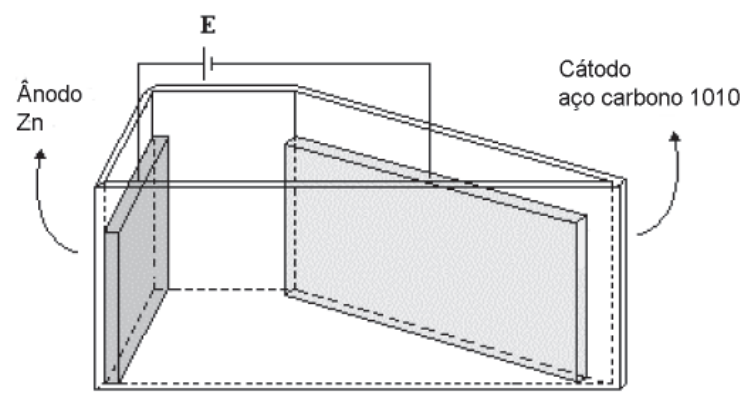

Figura 1. Diagrama esquemático da célula de Hull

por meio de ensaio de operação contínua durante $40 \mathrm{~h}$, sem reposição de constituintes, na temperatura ambiente e sob condições de controle galvanostático a $200 \mathrm{~A} \mathrm{~m}^{-2}$, selecionada a partir dos ensaios de célula de Hull. Paradas operacionais a cada 8 h de eletrólise foram programadas para coleta e análise de amostras, além de simular turnos de operação diária e semanal em uma indústria. Ensaios equivalentes foram feitos com os BACC e BALCC, para efeito de comparação.

Para estes ensaios foi confeccionada uma célula de vidro com capacidade para $300 \mathrm{~mL}$, sendo zinco comercial o ânodo e aço carbono 1010 (4,2 x 5 x 0,1 cm) o cátodo. A eletrodeposição foi feita nas duas faces do substrato. As análises químicas das amostras coletadas foram feitas utilizando-se as seguintes técnicas volumétricas: complexometria com EDTA para análise de zinco, argentimetria para análise de cianetos e precipitação e neutralização para análise de carbonato e hidróxido, respectivamente. O método volumétrico foi escolhido para estas análises por ser muito utilizado na prática industrial. Todas as análises químicas foram feitas, pelo menos, em triplicatas.

\section{Caracterização morfológica dos revestimentos}

A caracterização morfológica dos revestimentos foi feita utilizando um microscópio Philips modelo XL-30, obtendo-se micrografias com ampliações de 2500 e 8000 vezes para análises superficial e em seção transversal, respectivamente.

\section{RESULTADOS E DISCUSSÃO}

Os experimentos de célula de Hull foram feitos com correntes aplicadas de 0,$56 ; 1,26$ e 1,96 A, à temperatura ambiente e tempo de eletrodeposição de $5 \mathrm{~min}$, sendo que um painel típico eletrodepositado está mostrado na Figura 2, o qual foi obtido, com corrente aplicada de 1,26 A. Esta foto permite verificar que a camada eletrodepositada recobre toda a superfície do painel, não apresentando falhas nem descontinuidades.

A variação da densidade de corrente ao longo do painel, determinada a partir da Equação 1, está apresentada na Figura 3. Esta figura mostra que a densidade de corrente aumenta com a corrente aplicada e é decrescente ao longo do painel, sendo que este decréscimo se torna mais acentuado para maiores valores de correntes aplicadas. Por outro lado, a espessura da camada diminui gradual-

Tabela 1. Composição química dos banhos utilizados

\begin{tabular}{lccccc}
\hline Banho & $\begin{array}{l}\mathrm{ZnO} \\
\mathrm{g} \mathrm{L}^{-1}\end{array}$ & $\begin{array}{c}\mathrm{NaOH} \\
\mathrm{g} \mathrm{L}^{-1}\end{array}$ & $\begin{array}{c}\mathrm{NaCN} \\
\mathrm{g} \mathrm{L}^{-1}\end{array}$ & $\begin{array}{c}\mathrm{Na}_{2} \mathrm{CO}_{3} \\
\mathrm{~g} \mathrm{~L}^{-1}\end{array}$ & Aditivação \\
\hline BACC & 18,66 & 75,00 & 45,00 & - & Única \\
BALCC & 6,22 & 100,00 & - & - & Tripla \\
BALCE & 9,95 & 80,00 & - & $5,00-30,00$ & Única \\
\hline
\end{tabular}




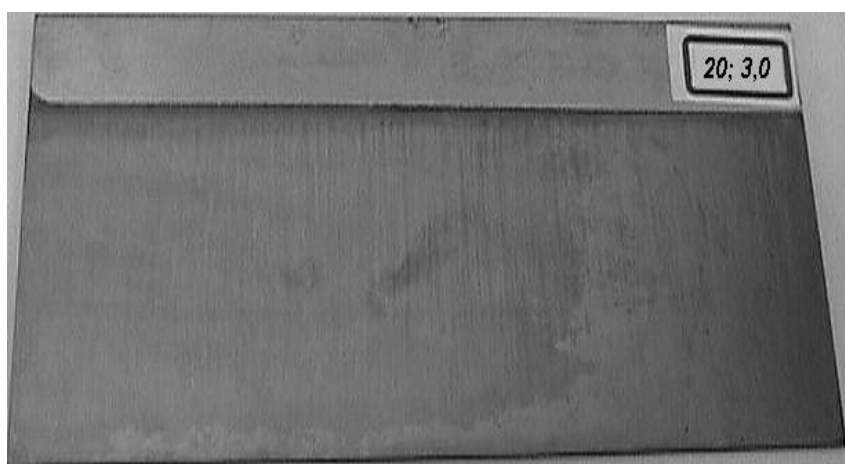

Figura 2. Painel característico obtido em célula de Hull

mente ao longo do painel da região de mais alta para a região de mais baixa densidade de corrente, como mostrado nas Figuras 3 e 4. O comportamento observado para a variação da densidade de corrente e da espessura ao longo do painel é explicado pelo aumento da resistividade da solução com o aumento gradual da distância entre o painel e o ânodo, devido à geometria da célula.

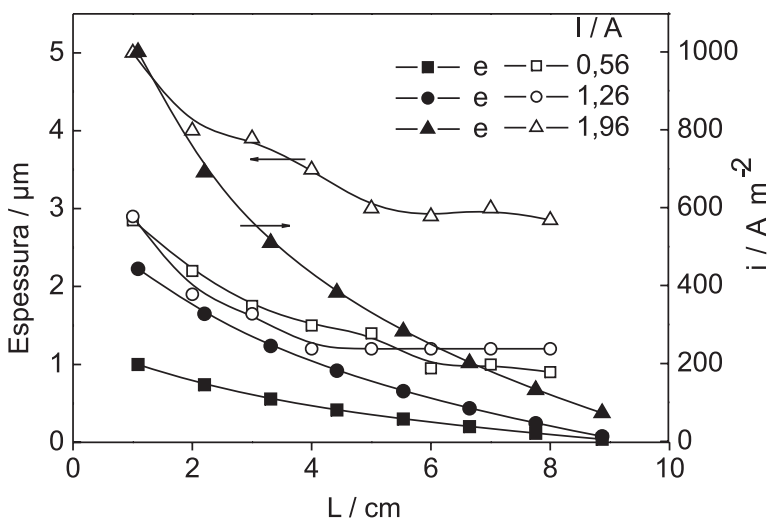

Figura 3. Variação da espessura da camada e da densidade de corrente ao longo do painel

A análise visual ao longo do painel foi feita para se poder correlacionar a faixa de densidade de corrente com a qualidade do revestimento. Acima de $500 \mathrm{~A} \mathrm{~m}^{-2}$ a camada era sem brilho, áspera e pouco aderente. A camada compreendida entre $100 \mathrm{e}$ $350 \mathrm{~A} \mathrm{~m}^{-2}$ apresentou aspecto metálico brilhante, sem manchas ou quaisquer outros defeitos, tendo sido esta considerada a melhor faixa de densidade de corrente operacional. Estas observações estão relacionadas ao desprendimento gasoso ao longo do painel. Elevadas densidades de corrente promovem altas taxas de evolução gasosa, conduzindo à formação de depósitos defeituosos e com espessura elevada. Em densidades de corrente menores, o desprendimento gasoso é menor, favorecendo a formação de depósitos mais homogêneos ou menos defeituosos.

A partir destes resultados e dos dados da Figura 4 foi possível calcular o rendimento catódico real do BALCE, utilizando a lei de Faraday $^{20}$. A Figura 5 mostra que o rendimento catódico é sempre decrescente com a densidade de corrente, sendo que este decréscimo é mais acentuado para densidades de corrente acima de $350 \mathrm{~A} \mathrm{~m}^{-2}$. Adicionalmente, este gráfico mostra que valores de densidades de corrente inferiores a $200 \mathrm{~A} \mathrm{~m}^{-2}$ apresentam eficiência catódica próxima a $100 \%$. Entretanto, na prática industrial opera-se sempre com uma densidade de corrente mediana entre os limites de densidade de corrente, onde é observada a melhor eletrodeposição. Isto se deve ao fato de, geralmente, as peças a serem revestidas apresentarem distintas geometrias

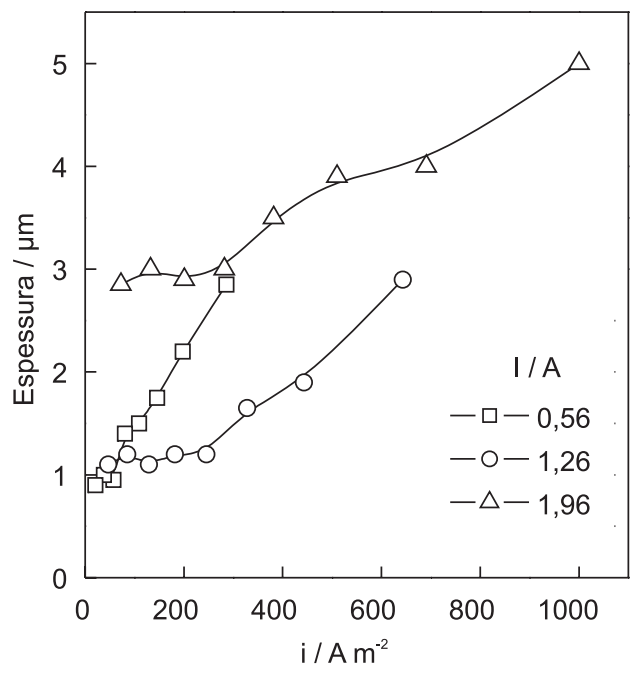

Figura 4. Variação da espessura da camada com a densidade de corrente

que levam ao surgimento de densidades de correntes diferentes e localizadas em regiões específicas das peças, tais como ressaltos, bordas, furos, reentrâncias, entre outros. Este procedimento visa garantir, no processo industrial, que toda a peça seja revestida no intervalo otimizado de densidade de corrente. Assim, foi selecionada a densidade de corrente de $200 \mathrm{~A} \mathrm{~m}^{-2}$, correspondendo a um rendimento catódico de aproximadamente $85 \%$, superior ao apresentado pelos banhos alcalinos cianídricos, que é ao redor de $82 \%{ }^{14,15}$, e é considerado elevado e ótimo para processos eletrolíticos industriais. Este resultado foi muito significativo, uma vez que a faixa de densidade de corrente selecionada a partir dos experimentos em célula de Hull, com diferentes correntes aplicadas $(0,56 ; 1,26$ e 1,96 A), coincidiu com elevados valores de rendimento.

As morfologias da superfície e da seção transversal dos revestimentos de Zn, obtidas a partir do BALCE, estão mostradas nas micrografias das Figuras 6 e 7, respectivamente. A micrografia da superfície (Figura 6) mostra uma camada de granulação fina, com formação de pequenos nódulos distribuídos uniformemente, não sendo observadas falhas nem descontinuidades em toda a extensão. Já a micrografia da seção transversal (Figura 7) mostra que a camada obtida é compacta e uniforme. Observa-se também a ausência de defeitos na interface

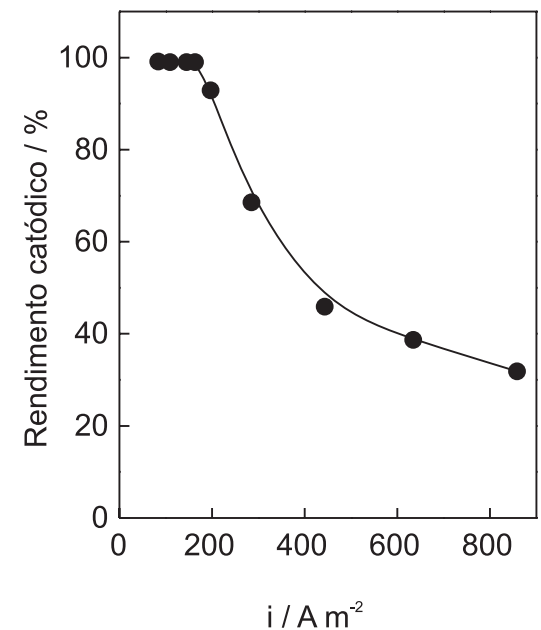

Figura 5. Rendimento catódico do banho em função da densidade de corrente aplicada 


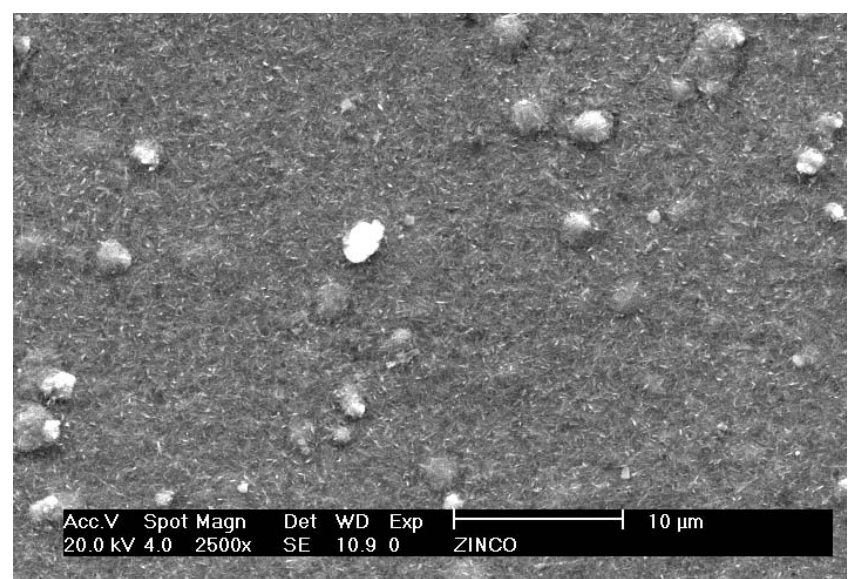

Figura 6. Micrografia típica obtida por MEV da superfície do zinco eletrodepositado a partir do BALCE

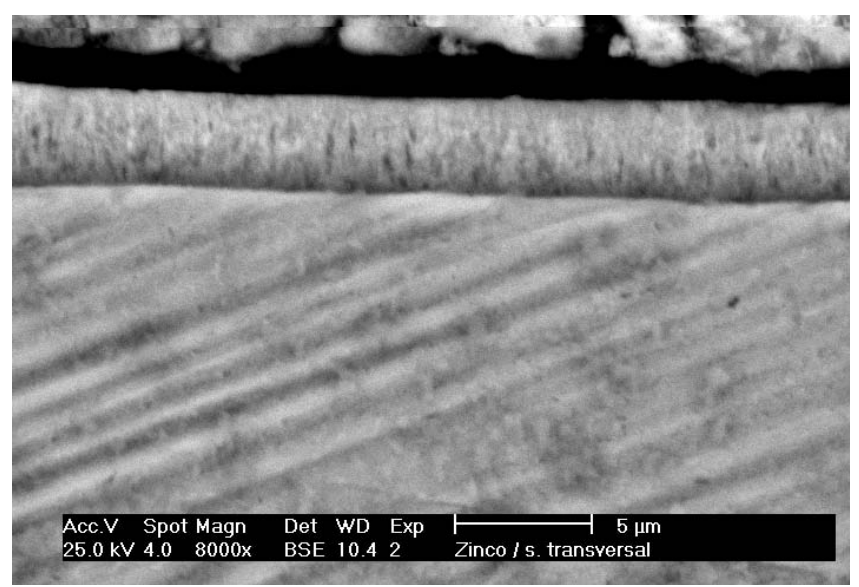

Figura 7. Micrografia obtida por MEV da seção transversal do zinco eletrodepositado a partir do BALCE

substrato/camada, sugerindo uma boa aderência da camada com o substrato.

A Figura 8 mostra os resultados dos experimentos de voltametria de varredura linear, onde a influência da concentração de $\mathrm{Na}_{2} \mathrm{CO}_{3}$ entre 5,0 a $30 \mathrm{~g} \mathrm{~L}^{-1}$ na reação de desprendimento de hidrogênio foi avaliada durante o processo de eletrodeposição. Observa-se que o aumento da concentração de $\mathrm{Na}_{2} \mathrm{CO}_{3}$ no eletrólito desloca o sobrepotencial da reação de desprendimento de hidrogênio para valores mais negativos no intervalo de 5 a $30 \mathrm{~g} \mathrm{~L}^{-1}$, sendo que este comportamento não foi mais observado para concentrações de carbonato superiores a $30 \mathrm{~g} \mathrm{~L}^{-1}$. Assim, estes resultados sugerem que o $\mathrm{Na}_{2} \mathrm{CO}_{3}$ contribui para o aumento do rendimento catódico pela redução do desprendimento gasoso.

Adicionalmente, foi observado em ensaios de células de Hull que a presença do carbonato no eletrólito levou à formação de depósitos mais brilhantes em toda a região de densidade de corrente selecionada, além de permitir estabelecer a otimização da concentração de carbonato de sódio no BALCE entre 25 e $30 \mathrm{~g} \mathrm{~L}^{-1}$.

As Figuras 9 a 11 apresentam os resultados da avaliação da estabilidade operacional do BALCE comparativamente aos banhos cianídrico e isento de cianetos convencional e mostram como variam as concentrações dos constituintes nos eletrólitos com o tempo de eletrólise. A análise comparativa dos resultados apresentados nas Figuras 9 e 10 mostra que o banho cianídrico apresenta os melhores resultados em relação à manutenção da concentração de zinco em solução, sendo crescente até atingir um máximo com 20 h de operação (Figura 9),

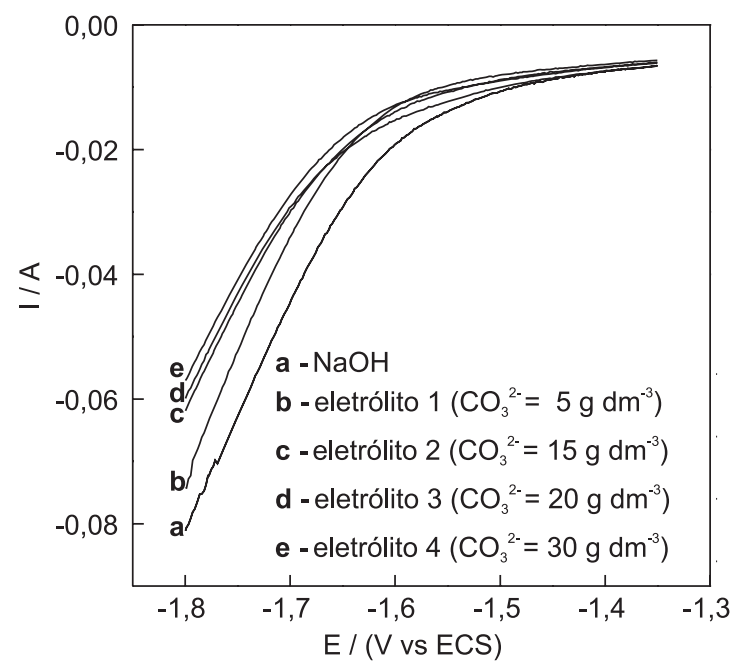

Figura 8. Curvas de polarização catódica em $\mathrm{NaOH} 80 \mathrm{~g} \mathrm{~L}^{-1}$ e diferentes concentrações de $\mathrm{CO}_{3}{ }^{2-}$

enquanto que a concentração de cianeto é sempre decrescente durante todo o período de operação (Figura 10). Este aumento de concentração de $\mathrm{Zn}^{2+}$ no banho evidencia a forte ação complexante que o íon cianeto exerce neste eletrólito ${ }^{12,14,19}$, pois neste intervalo de tempo operacional a concentração de $\mathrm{CN}^{-}$, em solução, ainda é suficiente para promover uma taxa de dissolução do ânodo $\mathrm{Zn}$ superior à taxa de deposição no cátodo. Após 20 h, a concentração de cianeto em solução já não é suficiente para manter a taxa de reposição de $\mathrm{Zn}^{2+}$ no banho igual ou superior à taxa de consumo de $\mathrm{Zn}^{2+}$, levando à redução da concentração de $\mathrm{Zn}^{2+}$ no banho. Por sua vez, a taxa de dissolução anódica do BALCE é idêntica à do banho comercial livre de cianeto e como este, em condições contínuas de operação, necessita de reposição metálica em períodos operacionais industriais mais curtos. Pode ser observado ainda na Figura 10 que a concentração de $\mathrm{Na}_{2} \mathrm{CO}_{3}$ no BALCE aumenta com o tempo de eletrólise, atingindo valores próximos a $60 \mathrm{~g} \mathrm{~L}^{-1}$, ou seja, mais que o dobro de sua concentração inicial. Este aumento de concentração de $\mathrm{Na}_{2} \mathrm{CO}_{3}$ provavelmente ocorre devido à reação entre o hidróxido de sódio do eletrólito e o $\mathrm{CO}_{2}$ gasoso dissolvido e não produz nenhum efeito prejudicial à formação dos

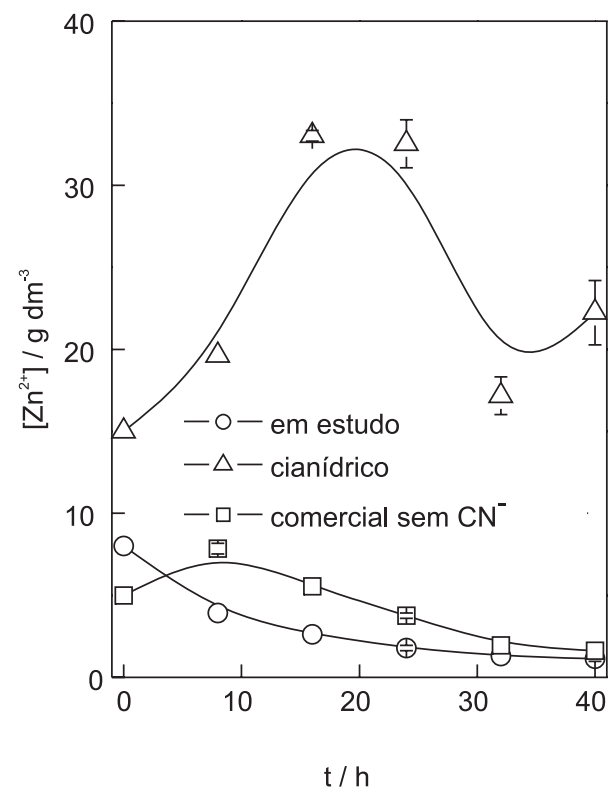

Figura 9. Variação comparativa da concentração de $\mathrm{Zn}^{2+}$ em solução com o tempo de eletrólise 


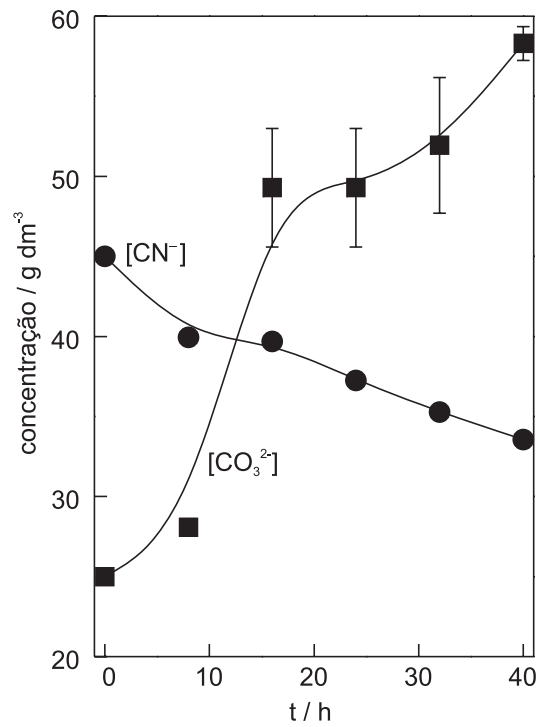

Figura 10. Variação da concentração de $\mathrm{CO}_{3}^{2-}$ e de $\mathrm{CN}^{-}$nos correspondentes banhos com o tempo de eletrólise

eletrodepósitos ${ }^{15}$. Na Figura 11 é mostrado o decréscimo de concentração de $\mathrm{NaOH}$ nos eletrólitos e verifica-se um comportamento semelhante entre eles, sendo sempre decrescente com o tempo de operação.

\section{ANÁLISE COMPARATIVA DE CUSTO}

A análise comparativa de custos de montagem e manutenção entre os banhos comerciais cianídricos e isentos de cianetos com o BALCE, quando submetidos a operação contínua por 40 h, está apresentada na Tabela 2. O custo de montagem foi calculado a partir das quantidades necessárias dos reagentes químicos comerciais utilizados na formulação do banho. O custo de manutenção foi calculado a partir da análise química do banho e refere-se às quantidades de reagentes a serem repostos após $40 \mathrm{~h}$ de operação contínua.

A análise desta tabela mostra que os custos de montagem e de manutenção do BALCE são semelhantes ao do banho cianídrico e bastante inferiores em relação ao banho comercial livre de cianeto. Adicionalmente, o BALCE tem a vantagem de não envolver custo para tratamento de efluentes contendo cianeto e, além disto, apresenta

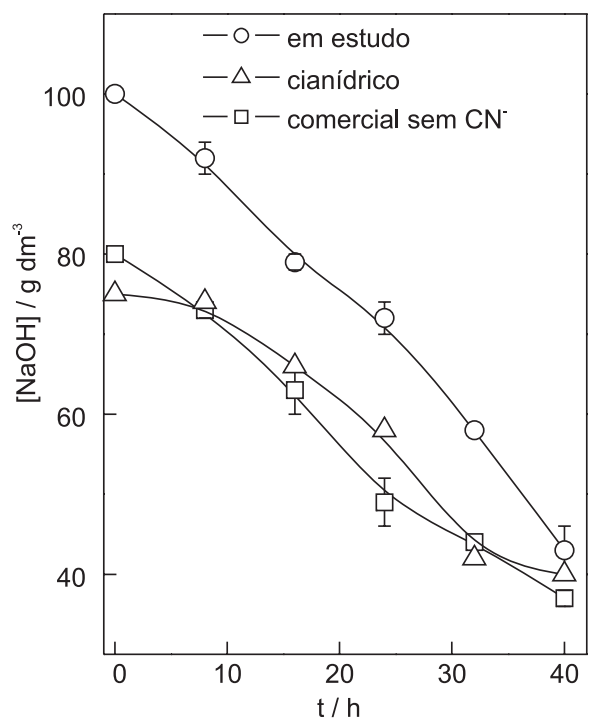

Figura 11. Variação comparativa da concentração de $\mathrm{NaOH}$ em solução com o tempo de eletrólise maior facilidade de controle operacional por utilizar um único aditivo ${ }^{14}$.

Tabela 2. Custos de montagem e manutenção para $1000 \mathrm{~L}$, para os banhos galvânicos industriais e o banho em estudo após 40 h de operação (valores de março de 2005, expressos em reais).

\begin{tabular}{lcc}
\hline Banho & Montagem / R\$ & Manutenção (40 h) / R\$ \\
\hline BACC & $1.360,00$ & 640,00 \\
BALCC & $2.060,00$ & $1.167,00$ \\
BALCE & $1.640,00$ & 680,00 \\
\hline
\end{tabular}

\section{CONCLUSÕES}

O BALCE foi eficiente para a obtenção de revestimentos de zinco, tendo com vantagens operacionais a ausência de complexantes orgânicos na formulação e uma boa eficiência catódica. Os parâmetros operacionais otimizados para o uso deste banho são densidade de corrente entre 100 e $350 \mathrm{~A} \mathrm{~m}^{-2}$ e concentração de carbonato no intervalo de 25 a $30 \mathrm{~g} \mathrm{~L}^{-1}$. A presença de $\mathrm{Na}_{2} \mathrm{CO}_{3}$ no BALCE possibilitou a operacionalidade com utilização de apenas um aditivo, sem necessidade de adição de aditivos condicionadores e redutores de tensão superficial, os quais elevam os custos de montagem e manutenção dos banhos alcalinos livres de cianetos comerciais.

Os custos de montagem e manutenção do banho proposto são comparáveis aos do banho cianídrico, mas se deve ressaltar que o tratamento dos resíduos do banho cianídrico é muito oneroso. Em contrapartida, o custo de montagem e reposição, do banho proposto é muito inferior ao do banho alcalino livre de cianetos comercial.

\section{AGRADECIMENTOS}

Ao CNPq, à CAPES, FUNCAP e FINEP pelo apoio financeiro recebido.

\section{REFERÊNCIAS}

1. Towsend, H. E.; Materials Performance 1991, 30, 60.

2. Natorsky, T. J.; Metal Finishing 1992, 90, 15.

3. Barceló, M.; Sarret, M.; Müller, C.; Pregonas, J.; Electrochim. Acta 1998, $43,13$.

4. Robbins, S. L.; Cotran, R. S.; Kumar, V.; Patologia estrutural e funcional, Ed. Guanabara: Rio de Janeiro, 1986.

5. Winand, R.; Electrochim. Acta 1994, 39, 1091.

6. Mackey, R. W. Em Modern Electroplating, Lowenheim, F. A., ed.; $3^{\text {rd }}$ ed. Wiley-Interscience Publication: New York, 1974, cap. 16

7. McGraw, L. D. Em ref. 6, cap. 16.

8. Kumar, C. S.; Muralidharan, V. S.; Begum, S. S.; Mayana, S. M.; Indian J. Chem. Technol. 2000, 7, 202.

9. Sekar, R.; Kala, C.; Krishnan, R. M.; Trans. Inst. Met. Finish. 2002, 80, 173.

10. Zuniga, V.; Ortega, R.; Meas, Y.; Trejo, G.; Plating and Surface Finishing 2004, 91, 46.

11. Rethinam, A. J.; Bapu, G. N. K. R.; Muralidharan, V. S.; Indian J. Chem. Technol. 2004, 11, 207.

12. Todt, H. G.; Trans. Inst. Metal Finish. 1973, 51, 91.

13. Lowenheim, F. A.; Electroplating, McGraw-Hill Book Company: New York, 1978, cap. 10 .

14. Budman, E.; Ventures, D.; Kearny, N. J.; Metal Finishing 1995, 93, 60.

15. Oplinger, F. F.; Bauch, F.; Trans. Electrochem. Soc. 1941, 80, 617.

16. Graham, A. K.; Met. Ind. 1938, 36, 279.

17. Foulke, D. G. Em ref. 6, cap. 22

18. Din 50957. Galvanisierungsprïfung. Mit Der Hull-Zelle. 1978

19. Lowenheim, F. A.; Electroplating, McGraw-Hill Book Company, 1978, cap. 2.

20. Atkins, P. W.; Físico-Química, 6 ${ }^{\mathrm{a}}$ ed., 1997, vol. 1, cap. 10.

21. Jager, A. V.; Tavares, M. F. M.; Quim. Nova 2001, 24, 363. 